\title{
Endoscopic management of tracheoesophageal fistulas
}

\author{
Daryl Ramaia , Alexis Bivona ${ }^{b}$, William Latson ${ }^{b}$, Andrew Ofosuc, Emmanuel Oforid, Madhavi Reddy ${ }^{d}$, \\ Douglas G. Adler ${ }^{\text {d }}$
}

The Brooklyn Hospital Center, NY; St George's University, True Blue, Grenada, WI; University of Utah School of Medicine, Huntsman Cancer Center, Salt Lake City, Utah, USA

\begin{abstract}
Tracheoesophageal fistulas (TEF) are pathologic communications between the trachea and esophagus. TEF can lead to significant respiratory distress that may result in lethal respiratory compromise, often due to recurrent and intractable infections. Through the use of endoscopy, some TEF can be successfully repaired using different approaches depending on the size, location, availability, and experience of the treating endoscopist. The aim of this manuscript is to provide an up-to-date review of the endoscopic management of TEF for gastroenterologists.
\end{abstract}

Keywords Tracheoesophageal fistula, endoscopy, stents, over-the-scope-clips, tissue adhesives

Ann Gastroenterol 2019; 32 (1): 1-6

\section{Introduction}

Tracheoesophageal fistulas (TEF) are abnormal, pathologic communications between the posterior wall of the trachea and the anterior wall of the esophagus. TEF can be congenital or acquired, as well as benign or malignant. Most TEF in adults are acquired; congenital TEF are more commonly associated with esophageal atresia at birth. The majority of acquired TEF are due to esophageal and pulmonary malignancies. Other benign etiologies, such as caustic ingestion, prolonged esophageal intubation and surgical interventions, can lead to TEF formation [1-3].

TEF can be managed either surgically (open repair or thoracoscopic) or endoscopically, depending on their etiology, size, anatomy, and patient comorbidities [4]. Surgery is highly invasive and other options are typically investigated before this is undertaken. Endoscopic therapy has been shown to be a safe and effective approach in the management of TEF, with lower

${ }^{a}$ Department of Medicine, The Brooklyn Hospital Center, NY (Daryl Ramai); 'bchool of Medicine, St George's University, True Blue, Grenada, WI (Alexis Bivona, William Latson); 'Division of Gastroenterology and Hepatology, The Brooklyn Hospital Center, NY (Andrew Ofosu); ${ }^{\mathrm{d} D i v i s i o n}$ of Gastroenterology and Hepatology, University of Utah School of Medicine, Huntsman Cancer Center, Salt Lake City, Utah (Emmanuel Ofori, Madhavi Reddy, Douglas G. Adler), USA

Conflict of Interest: None

Correspondence to: Douglas G. Adler MD, FACG, AGAF, FASGE, Division of Gastroenterology and Hepatology, University of Utah School of Medicine, Huntsman Cancer Center, Salt Lake City, Utah, e-mail: Douglas.adler@hsc.utah.edu

Received 26 July 2018; accepted 24 September 2018; published online 29 October 2018

DOI: https://doi.org/10.20524/aog.2018.0321 morbidity and mortality compared to surgical interventions [5]. With rapid advances in therapeutic endoscopy, new techniques have emerged that can be used to successfully manage and repair TEF.

\section{Endoscopic management}

\section{Esophageal stents}

Esophageal stents are routinely used in an attempt to close and manage TEF [6]. Stents should be placed to cover the TEF as well as short sections of normal esophageal tissue both proximal and distal to the fistula. It must be stressed that esophageal stents do not provide an airtight seal over the TEF and aspiration can occur even in the setting of a perfectly placed esophageal stent (Fig. 1,2).

There are two basic types of stents available to endoscopists: self-expanding metal stents (SEMS) and silicone or plasticbased self-expanding stents; the latter have been largely abandoned in current practice and will not be discussed further. Self-expanding stents have the capacity to expand themselves more precisely into the lumen of the esophagus or trachea; they can theoretically fit most airway malformations [7]. Stents are available in two forms: partially covered and fully covered. Cover materials (such as silicone, polyurethane, and most commonly polytetrafluoroethylene) reduce reintervention rates, which range from $30-50 \%$ for uncovered stents, primarily because of complications from granulation tissue ingrowth [8]. To close a TEF, a covered or partially covered stent must be used.

SEMS have shown varying degrees of clinical success when used to treat TEF, ranging from $67-100 \%$ [9]. In a multitechnique, multicenter study of endoscopic TEF closure, Silon 


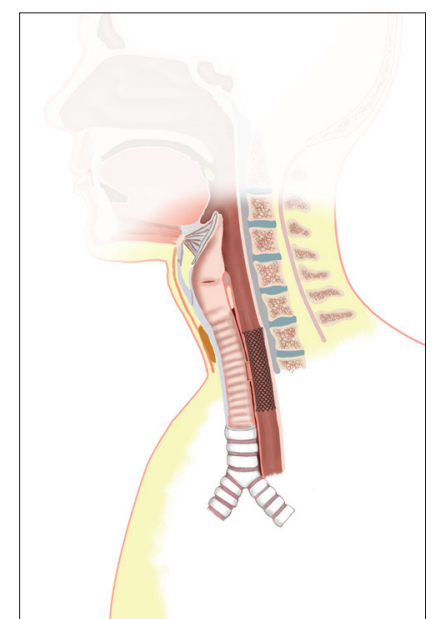

Figure 1 Schematic diagram of tracheoesophageal fistula with an esophageal stent

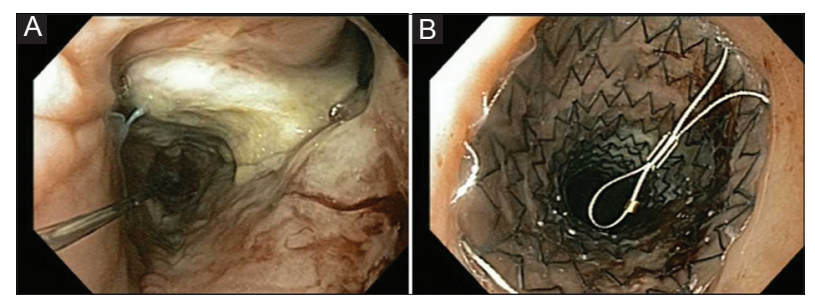

Figure 2 (A) Endoscopic image of a large tracheoesophageal fistula that developed following esophagectomy. (B) Same patient after placement of a self-expanding metal stent across the fistula

et al reported the use of SEMS in $92 \%$ of patients $(n=25)$ and $85.7 \%$ of procedures $(n=35)$. All were placed under general anesthesia and $88.9 \%$ were placed using fluoroscopic guidance. SEMS used as monotherapy showed a high technical success rate $(\mathrm{n}=13 ; 92.3 \%)$ and a relatively moderate clinical success rate $(n=13 ; 53.8 \%)$. Five patients $(38.5 \%)$ required additional procedures because of stent migration and aspiration $(n=1)$, persistent fistula without aspiration $(\mathrm{n}=1)$, and aspiration with the stent remaining in situ $(\mathrm{n}=3)$. After five secondary interventions, clinical success was $80 \%$ (4/5). Secondary interventions included replacing esophageal stents, replacing an esophageal stent with over-the-scope clips (OTSC), and replacing with OTSC, a new esophageal stent, and an airway Y stent.

While esophageal SEMS are minimally invasive and are often associated with positive outcomes and improved quality of life, they are sometimes more effective when used in combination with other therapies, such as an airway Y stent or an OTSC [10]. The Y or bifurcation airway stent is typically used for conditions affecting the lower trachea, carina or the proximal bronchial lumen that may lead to airway obstruction or airway fistulation [11].

Combined therapy with tracheal and esophageal stents is useful and is indicated in the following instances: 1) esophageal stenting could compromise the respiratory tract via extrinsic compression; 2) if there is preexisting tracheal stenosis, in which case the airway stent should be deployed first; and 3) cases of large fistulas (>20 mm) $[7,10,12]$. The study by Silon et al used tracheal stents in combination with esophageal stents as initial therapy in 6 patients. Esophageal stents were used for proximal fistulas while tracheal stents were used for proximal, middle, and distal fistulas. The technical success using this approach was $100 \%$, while the clinical success rate remained low (33.3\%), highlighting the difficulties in treating these lesions.

Adverse events associated with SEMS include migration following deployment, as well as symptoms of cough, dysphagia, nausea, gastroesophageal reflux, bleeding, perforation, pneumonia, tracheal compression and chest pain $[6,7]$. The frequency of chest pain after stent insertion has been estimated to be $5-50 \%$, depending on how it is defined and studied [13]. Likewise, the frequency of stent migration can be as high as $40 \%$, with the migration rate being higher with plastic or silicone stents $[14,15]$.

\section{Tissue adhesives: fibrin glue and cyanoacrylate}

As an alternative to stents, endoscopists may revert to using sealants or tissue adhesives. The most commonly used sealants used in gastrointestinal endoscopy include cyanoacrylates, fibrin glues, and thrombin [16]. Cyanoacrylates are a class of sealants that solidify rapidly in the presence of a weak base, such as water or blood [17]. Fibrin glues are composed of highly purified, freeze-dried human fibrinogen with factor XIII in addition to a starter solution containing human thrombin. Upon mixing, the solution forms a clot that replicates the terminal phase of the clotting cascade [18]. Additionally, the use of commercial thrombin promotes the conversion of fibrinogen to fibrin [19]. This ultimately produces cross-linked fibrin polymers and a closed seal over the fistula.

Several case series have demonstrated successful outcomes following the use of cyanoacrylates for fistula repair; however, randomized control trials are lacking [20-22]. A systematic review compared the use of sealant with or without abrasion (23 articles and 57 pediatric patients) versus open surgery (21 articles and 108 patients) for managing recurrent TEF [4]. The study characterized the efficacy of each treatment via standardized comparison in 3 categories: single successful treatments, mean number of treatments performed, and treatment failures converted to an alternative procedure. In the endoscopic group, the sealant-only cohort $(n=6)$ was found to be the most successful single treatment $(n=4 / 6,67 \%)$, having the least average number of treatments required (1.5) and treatment failures $(n=1 / 6,16.6 \%)$. However, it should be noted that the sealant-only cohort had a relatively small number of patients, which should be considered when interpreting the results.

There are other reports of relatively low success rates when sealant is used alone compared to higher rates in combination with other therapies [5]. Richter et al showed that sealant (fibrin with added aprotinin) combined with abrasion techniques had a higher success rate $(\mathrm{n}=15,93.3 \%)$ compared to abrasion alone $(n=8,62.5 \%)$ and sealant alone $(n=14,78.6 \%)$ [23].

Gregory et al identified 11 studies involving 30 patients treated for recurrent TEF. The review found that combination therapy with fibrin glue and electrocautery was more effective 
when compared to electrocautery alone: $86 \%$ and $67 \%$, respectively [24]. Combination therapy was a safe alternative to open surgical repair, as only three patients experienced respiratory distress syndrome and one patient required a tracheostomy [24]. Other studies support and recommend the use of fibrin glue in combination with abrasive therapy as providing the best outcomes [25,26]. Additionally, societies such as the American Society for Gastrointestinal Endoscopy report that fibrin glue provides endoscopists with ease of use without any risk of damage to the endoscope [27].

\section{Endoscopic clips}

Endoscopic clips were originally designed to function as hemostatic devices, specifically in the gastrointestinal tract [28]. The through-the-scope clip system was the original iteration of endoscopic clips, but was limited by relatively small opening diameters and a sometimes suboptimal closure force [29,30]. The OTSC system was designed to overcome these limitations. Since then, several different clip shapes and sizes have been developed for use in different organs and different clinical contexts [8]. Other innovative clips, such as the Padlock Clip, have emerged and have been successfully utilized in the repair of TEF $[31,32]$.

The technical overall success rate achieved by OTSC devices remains unclear. Haito-Chavez et al reported a large study involving 108 fistulas, 48 perforations, and 32 leaks. Of these, 16 cases involved esophageal fistulas, of which 6 resulted in technical failure [33]. It was hypothesized that the failure was due to fibrotic or retracted edges, which impeded an adequate opposition of defect borders. Additionally, using multivariate logistic regression, the study reported that the most important predictor of long-term success after OTSC closure was the type of defect, failure being reported most commonly in patients with fistulas. The study concluded that OTSC was more clinically successful in managing leaks and perforations.

In addition, we identified 10 case studies that specifically described the use of OTSC in the repair of TEF. All 10 cases were technically and clinically successful [31,32,34-40]. Almost all cases (9/10) used a single clip for primary (6/10) or secondary (4/10) intervention. Follow-up time ranged from 2 weeks to 8 months and only one case reported a complication of clip dislodgement (Table 1).

While information abounds on the use of OTSC in the repair of gastrointestinal leaks and perforations, data on the use of OTSC for repairing TEF remains sparse. As a result, the role of OTSC in the management of TEF remains unclear. Larger clinical studies are needed to evaluate its long-term clinical and technical efficacy compared to other endoscopic interventions.

\section{Atrial septal defect (ASD) occluder devices}

In cases where there is extensive fibrosis not amendable to the application of clips or adhesives, ASD occluder devices, namely the Amplatzer Occluder (Amplatzer Occluder; AGA

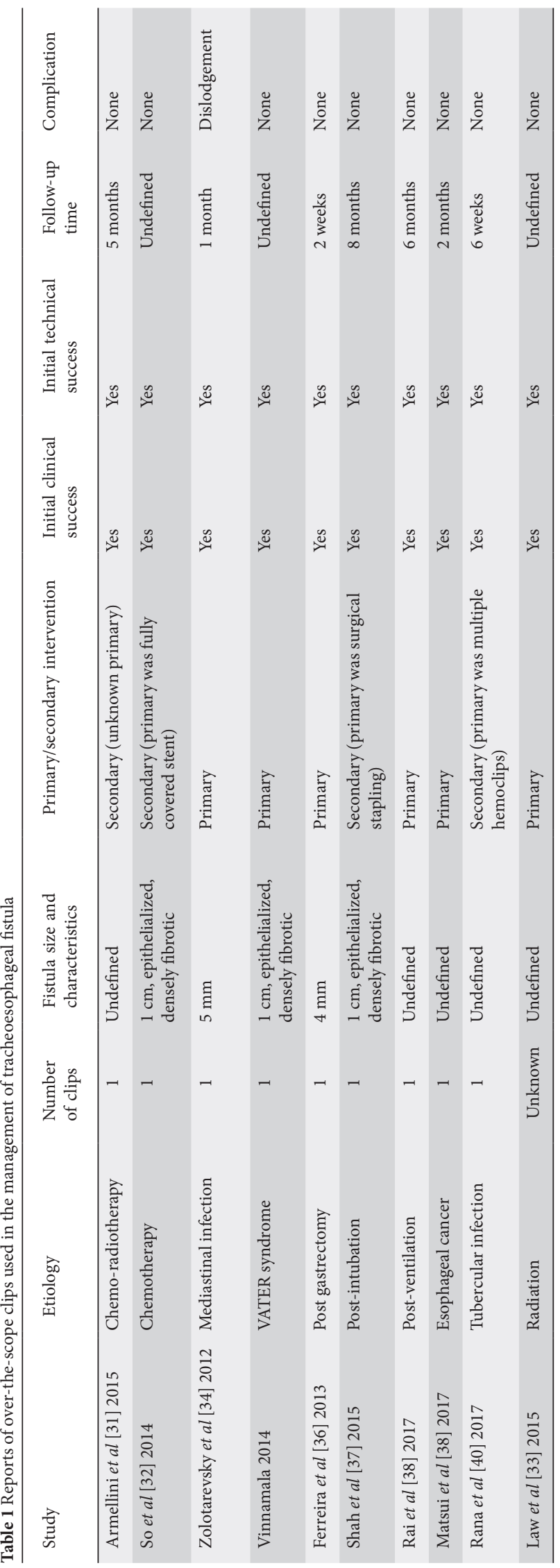


Medical Corp, Plymouth, MN), can be considered as an option to manage TEF. An ASD occluder device is a permanently implanted prosthetic that forms a mechanical barrier between the esophagus and trachea; it is supplied along with a catheter delivery system. The Amplatzer device consists of two polyester-coated nitinol discs connected via a thin waist and loaded into a catheter. The diameter of the discs typically ranges from $1-2 \mathrm{~cm}$ and can be matched to the size of the fistula. The discs are coated with polytetrafluoroethylene material, giving them a microporous surface that facilitates coverage by fibrous connective tissue and ultimately adapts to the patient's anatomy [41].

When the device is deployed, each ring expands on either side of the fistula, thus fixing it in place [42]. They can be used for temporary alleviation of a patient's symptoms while on mechanical ventilation, or for long-term management [43]. ASD occluder devices facilitate granulation after 1-6 months, allowing their effective usage in long-term management [44-46].

In 2010, Repici et al described the first use of TEF closure using an ASD occluder device in a 58-year-old male patient with a malignant recurrent TEF that occurred after intrathoracic anastomosis for an adenocarcinoma in the esophagus. This technique facilitated successful closure after unsuccessful endoscopic and surgical interventions. Fistula closure and granulation were confirmed at an 8-month follow up [47]. Cohen-Atsmoni et al described 2 patients with acquired TEF due to prolonged intubation, managed using this technique [43]. In total, only 6 successful cases have been reported of TEF closure using an ASD occluder device, demonstrating that this is largely an experimental technique in gastrointestinal endoscopy [44,47-51]. The most commonly reported complications associated with this technique are migration due to an incorrectly sized device, esophageal peristalsis, extrusion, or enlargement of the fistula $[48,49]$. No multi-patient studies have been reported and further studies are needed to fully evaluate the efficacy of this technique. Until the role of the ASD occluder is established in the management of TEF, it can be considered in extreme cases of TEF not amenable to other techniques.

\section{Endoluminal vacuum-assisted closure (EVAC) therapy}

EVAC is another technique which can potentially be used in the repair of TEF and other upper gastrointestinal defects [50,51]. EVAC creates a negative pressure environment while placing a polyurethane sponge in the lumen of the fistula. The sponge is connected via a nasogastric tube that continuously removes secretions and improves microcirculation. The process induces the accelerated formation of granulation tissue, which leads to closure of the lesion or fistula $[52,53]$. Though this technique has been used sparingly and reports are sparse, several case reports describe its use to successfully treat acquired TEF [54-58]. However, as with the ASD occluder device, large retrospective or prospective cohort studies are needed to establish its role in the management of TEF.

\section{Concluding remarks}

TEF can be congenital or acquired, as well as benign or malignant. Today there are a variety of endoscopic techniques that can be safely employed by endoscopists, surgeons, and respirologists to repair TEF. Clinicians may select an approach based upon the size of the fistula, location, availability and their experience. While some techniques are associated with minor adverse effects, these are rare. As of today, there are no official guidelines for repairing TEF, primarily because of the small number of cases reported [Q: Please check that this is the correct intended meaning] and the variable clinical success, which does not allow generalization. The endoscopic repair of TEF follows an underlying narrative throughout treatment strategies: combined approaches are more successful. Large head-to-head clinical studies are needed to compare and further extrapolate the longterm clinical and technical efficacy of these therapeutic strategies.

\section{Acknowledgment}

We would like to thank Mr. Sahrin Samad for the medical illustration.

\section{References}

1. Reed MF, Mathisen DJ. Tracheoesophageal fistula. Chest Surg Clin N Am 2003;13:271-289.

2. Chen YH, Li SH, Chiu YC, et al. Comparative study of esophageal stent and feeding gastrostomy/jejunostomy for tracheoesophageal fistula caused by esophageal squamous cell carcinoma. PLoS One 2012;7:e42766.

3. Balazs A, Kupcsulik PK, Galambos Z. Esophagorespiratory fistulas of tumorous origin. Non-operative management of 264 cases in a 20-year period. Eur J Cardiothorac Surg 2008;34:1103-1107.

4. Aworanti O, Awadalla S. Management of recurrent tracheoesophageal fistulas: a systematic review. Eur J Pediatr Surg 2014;24:365-375.

5. Meier JD, Sulman CG, Almond PS, Holinger LD. Endoscopic management of recurrent congenital tracheoesophageal fistula: a review of techniques and results. Int J Pediatr Otorhinolaryngol 2007;71:691-697.

6. Ross WA, Lee JH. Endoscopic approach to tracheoesophageal fistulas in adults. Tech Gastrointest Endosc 2008;10:155-163.

7. Ke M, Wu X, Zeng J. The treatment strategy for tracheoesophageal fistula. J Thorac Dis 2015;7:S389-S397.

8. Banerjee S, Barth BA, Bhat YM, et al; ASGE Technology Committee. Endoscopic closure devices. Gastrointest Endosc 2012;76:244-251.

9. Silon B, Siddiqui AA, Taylor LJ, Arastu S, Soomro A, Adler DG. Endoscopic management of esophagorespiratory fistulas: a multicenter retrospective study of techniques and outcomes. Dig Dis Sci 2017;62:424-431.

10. Najran P, Mullan D, Shepherd D, Li A, Laasch HU. Minimally invasive treatment strategies for tracheoesophageal fistulae. Dig Dis Interv 2018;02:11-17.

11. Madan K, Dhooria S, Sehgal IS, et al. A multicenter experience with the placement of self-expanding metallic tracheobronchial Y stents. J Bronchology Interv Pulmonol 2016;23:29-38.

12. Nomori H, Horio H, Imazu Y, Suemasu K. Double stenting for 
esophageal and tracheobronchial stenoses. Ann Thorac Surg 2000;70:1803-1807.

13. Kujawski K, Stasiak M, Rysz J. The evaluation of esophageal stenting complications in palliative treatment of dysphagia related to esophageal cancer. Med Sci Monit 2012;18:CR323-CR329.

14. Suzuki T, Siddiqui A, Taylor LJ, et al. Clinical outcomes, efficacy, and adverse events in patients undergoing esophageal stent placement for benign indications. J Clin Gastroenterol 2016;50:373-378.

15. Dasari BV, Neely D, Kennedy A, et al. The role of esophageal stents in the management of esophageal anastomotic leaks and benign esophageal perforations. Ann Surg 2014;259:852-860.

16. Ryou M, Thompson CC. Tissue adhesives: a review. Tech Gastrointest Endosc 2006;8:33-37.

17. Seewald S, Sriram PV, Naga M, et al. Cyanoacrylate glue in gastric variceal bleeding. Endoscopy 2002;34:926-932.

18. Reiner AP. Fibrin glue increasingly popular for topical surgical hemostasis. Lab Med 2015;30:189-193.

19. Kotzampassi K, Eleftheriadis E. Tissue sealants in endoscopic applications for anastomotic leakage during a 25 -year period. Surgery 2015;157:79-86.

20. Seewald S, Brand B, Groth S, et al. Endoscopic sealing of pancreatic fistula by using N-butyl-2-cyanoacrylate. Gastrointest Endosc 2004;59:463-470.

21. Labori KJ, Trondsen E, Buanes T, Hauge T. Endoscopic sealing of pancreatic fistulas: four case reports and review of the literature. Scand J Gastroenterol 2009;44:1491-1496.

22. Mutignani M, Tringali A, Khodadadian E, et al. External pancreatic fistulas resistant to conventional endoscopic therapy: endoscopic closure with N-butyl-2-cyanoacrylate (Glubran 2). Endoscopy 2004;36:738-742.

23. Richter GT, Ryckman F, Brown RL, Rutter MJ. Endoscopic management of recurrent tracheoesophageal fistula. J Pediatr Surg 2008;43:238-245.

24. Gregory S, Chun RH, Parakininkas D, et al. Endoscopic esophageal and tracheal cauterization for closure of recurrent tracheoesophageal fistula: A case report and review of the literature. Int J Pediatr Otorhinolaryngol 2017;98:158-161.

25. Kawabata H, Okazaki Y, Inoue N, et al. Endoscopic closure of an anastomo-cutaneous fistula: Filling and shielding using polyglycolic acid sheets and fibrin glue with easily deliverable technique. Endosc Int Open 2018;6:E994-E997.

26. Gutiérrez San Román C, Barrios JE, Lluna J, et al. Long-term assessment of the treatment of recurrent tracheoesophageal fistula with fibrin glue associated with diathermy. J Pediatr Surg 2006;41:1870-1873.

27. Bhat YM, Banerjee S, Barth BA, et al; ASGE Technology Committee. Tissue adhesives: cyanoacrylate glue and fibrin sealant. Gastrointest Endosc 2013;78:209-215.

28. Weiland T, Fehlker M, Gottwald T, Schurr MO. Performance of the OTSC System in the endoscopic closure of gastrointestinal fistulae-a meta-analysis. Minim Invasive Ther Allied Technol 2012;21:249-258.

29. Repici A, Arezzo A, De Caro G, et al. Clinical experience with a new endoscopic over-the-scope clip system for use in the GI tract. Dig Liver Dis 2009;41:406-410.

30. Baron TH, Song LM, Ross A, Tokar JL, Irani S, Kozarek RA. Use of an over-the-scope clipping device: multicenter retrospective results of the first U.S. experience (with videos). Gastrointest Endosc 2012;76:202-208.

31. Armellini E, Crinò SF, Orsello $M$, et al. New endoscopic over-the-scope clip system for treatment of a chronic postsurgical tracheoesophageal fistula. Endoscopy 2015;47(Suppl 1 UCTN):E437-E438.

32. So BJ, Adler DG. Closure of a chronic, non-healing tracheoesophageal fistula with a new over-the-scope clip. ACG Case Rep J 2014;2:18-20.

33. Haito-Chavez Y, Law JK, Kratt T, et al. International multicenter experience with an over-the-scope clipping device for endoscopic management of GI defects (with video). Gastrointest Endosc 2014;80:610-622.

34. Zolotarevsky E, Kwon Y, Bains M, Schattner M. Esophagobronchial fistula closure using a novel endoscopic over-the-scope-clip. Ann Thorac Surg 2012;94:e69-e70.

35. Vinnamala S, Murthy B, Parmar J, et al. Rendezvous technique using bronchoscopy and gastroscopy to close a tracheoesophageal fistula by placement of an over-the-scope clip. Endoscopy 2014;46(Suppl 1 UCTN):E301.

36. Noronha Ferreira C, Ribeiro LC, Velosa J, et al. Total gastrectomy in an elderly patient complicated by esophageal fistula: rescue by the over-the-scope clip. Gastrointest Endosc 2013;77:497-498.

37. Shah SK. Use of a double-channel endoscope for closure of a surgically failed chronic benign tracheoesophageal fistula using over-the-scope-clip. J Dig Endosc 2015;6:32-34.

38. Rai P, Bhargava R. Successful closure of post-tracheostomy large chronic tracheoesophageal fistula with new over-the-scope clip. J Dig Endosc 2017:29:634.

39. Matsui S, Kashida H, Asakuma Y, Kudo M. Endoscopic treatment of tracheoesophageal fistula using the over-the-scope-clip system. Ann Gastroenterol 2017;30:578.

40. Rana SS, Mandavdhare H, Sharma V, et al. Successful closure of chronic, nonhealing tubercular esophagobronchial fistula with an over-the-scope clip. J Dig Endos 2017;8:33-35.

41. Mejia Perez LK, Confer B, Veniero J, Raymond D, Bhatt A. Closure of a persistent esophagopleural fistula by use of an atrial septal occluder device. VideoGIE 2016;1:27-28.

42. AMPLATZER ${ }^{\text {mix }}$ Septal Occluder. St. Jude Medical. 2018; Available from: https://www.sjm.com/en/professionals/featured-products/ structural-heart/structural-heart-occluders/asd-closure-devices/ amplatzer-septal-occluder [Accessed October 9, 2018].

43. Cohen-Atsmoni S, Tamir A, Avni Y, Priel IE, Roth Y. Endoscopic occlusion of tracheoesophageal fistula in ventilated patients using an amplatzer septal occluder. Indian J Otolaryngol Head Neck Surg 2015;67:196-199.

44. Scordamaglio PR, Tedde ML, Minamoto H, Pedra CA, Jatene FB. Endoscopic treatment of tracheobronchial tree fistulas using atrial septal defect occluders: preliminary results. J Bras Pneumol 2009;35:1156-1160.

45. Boudoulas KD, Elinoff J, Resar JR. Bronchopulmonary fistula closure with an Amplatzer Multi-Fenestrated Septal Occluder. Catheter Cardiovasc Interv 2010;75:455-458.

46. Tedde ML, Scordamaglio PR, Minamoto H, Figueiredo VR, Pedra CC, Jatene FB. Endobronchial closure of total bronchopleural fistula with Occlutech Figulla ASD N device. Ann Thorac Surg 2009;88:e25-e26.

47. Repici A, Presbitero P, Carlino A, et al. First human case of esophagus-tracheal fistula closure by using a cardiac septal occluder (with video). Gastrointest Endosc 2010;71:867-869.

48. Coppola F, Boccuzzi G, Rossi G, Gaia S, Cosimato M, Recchia S. Cardiac septal umbrella for closure of a tracheoesophageal fistula. Endoscopy 2010;42(Suppl 2):E318-E319.

49. Miller PE, Arias S, Lee H, Yarmus L, Feller-Kopman D. Complications associated with the use of the amplatzer device for the management of tracheoesophageal fistula. Ann Am Thorac Soc 2014;11:1507-1509.

50. Laukoetter MG, Mennigen R, Neumann PA, et al. Successful closure of defects in the upper gastrointestinal tract by endoscopic vacuum therapy (EVT): a prospective cohort study. Surg Endosc 2017;31:2687-2696.

51. Youn HC, Kwon SH. Endoscopic vacuum-assisted closure (E-VAC) treatment in a patient with delayed anastomotic perforation following a perforated gastric conduit repair after an Ivor-Lewis esophagectomy. Ann Thorac Cardiovasc Surg 2016;22:363-366.

52. Venturi ML, Attinger CE, Mesbahi AN, Hess CL, Graw KS. 
Mechanisms and clinical applications of the vacuum-assisted closure (VAC) device: a review. Am J Clin Dermatol 2005;6:185-194.

53. Pines G, Bar I, Elami A, et al. Modified endoscopic vacuum therapy for nonhealing esophageal anastomotic leak: technique description and review of literature. J Laparoendosc Adv Surg Tech A 2018;28:33-40.

54. Lee HJ, Lee H. Endoscopic vacuum-assisted closure with sponge for esophagotracheal fistula after esophagectomy. Surg Laparosc Endosc Percutan Tech 2015;25:e76-e77.

55. Smallwood NR, Fleshman JW, Leeds SG, Burdick JS. The use of endoluminal vacuum (E-Vac) therapy in the management of upper gastrointestinal leaks and perforations. Surg Endosc 2016;30:2473-2480.

56. Möschler O, Nies C, Mueller MK. Endoscopic vacuum therapy for esophageal perforations and leakages. Endosc Int Open 2015;3:E554-E558.

57. Heits N, Stapel L, Reichert B, et al. Endoscopic endoluminal vacuum therapy in esophageal perforation. Ann Thorac Surg 2014;97:1029-1035.

58. Bludau M, Hölscher AH, Herbold T, et al. Management of upper intestinal leaks using an endoscopic vacuum-assisted closure system (E-VAC). Surg Endosc 2014;28:896-901. 